\title{
Thermal isostasy and deformation of possible paleoshorelines on Mars
}

\author{
Javier Ruiz $^{\mathrm{a}, *}$, Alberto G. Fairén ${ }^{\mathrm{b}}$, James M. Dohm ${ }^{\mathrm{c}}$, Rosa Tejero ${ }^{\mathrm{a}}$ \\ ${ }^{a}$ Departamento de Geodinámica, Facultad de Ciencias Geológicas, Universidad Complutense de Madrid, Madrid 28040, Spain \\ ${ }^{\mathrm{b}}$ Centro de Biología Molecuar, CSIC-Universidad Autónoma de Madrid, Cantoblanco, Madrid 28049, Spain \\ ${ }^{\mathrm{c} D e p a r t m e n t}$ of Hydrology and Water Resources, University of Arizona, Tucson, AZ 85721, USA
}

\begin{abstract}
Variations in martian surface heat flow, similar to those observed in terrestrial continental tectonothermally stable areas, could result in elevation differences of kilometric scale through differential thermal isostasy. This effect is enhanced with the increase of heat sources located within the crust. Local differences in the thermal history of the Mars' lithosphere could have appreciably distorted the original long-wavelength topography of putative martian paleoshorelines. So, this work shows that a paleoequipotential surface does not necessarily have to fit well a present-day equipotential surface when evaluating paleoshorelines through assessment of high-resolution topography.
\end{abstract}

1 .

Keywords: Mars; Thermal isostasy; Paleoshorelines; Heat flow; Equipotential surfaces

\section{Introduction}

A significant relation exists between Earth's surface elevation and the thermal state of the lithosphere: the warmer the lithosphere, the lower its mean density and the higher its buoyancy with respect to the underlying asthenosphere materials. This principle (known as thermal isostasy) has been broadly applied to the thermal subsidence of the cooling oceanic lithosphere (e.g., Turcotte and Schubert, 2002), but it can also be applied in a general way to the continental lithosphere (Lachenbruch and Morgan, 1990), including a tectonothermally stable one. This allows the use of topography and surface heat flow data to constrain Earth's continental lithospheric thermal structure (e.g., Tejero and Ruiz, 2002; Lewis et al., 2003). This relation must also be valid for Mars (Ruiz, 2003; Ruiz et al., 2003). In

\footnotetext{
*Corresponding author. Fax: + 34913944845.

E-mail address: jaruiz@geo.ucm.es (J. Ruiz).
}

this work, we argue that different thermal isostasy histories among regions may have contributed to the deformation of the original paleotopographic signatures of possible martian paleoshorelines.

Several investigators have proposed the possible existence of large bodies of water in the northern plains of Mars that range from oceans (Parker et al., 1989, 1993; Clifford and Parker, 2001) to lakes (Scott et al., 1995), and several paleoshorelines have been proposed. While Malin and Edgett $(1999,2001)$ indicate that there is not sufficient evidence to support the shoreline hypothesis through analysis of high-resolution MOC imagery targeted in specific putative shoreline localities, other investigators present arguments that dispute these findings (Parker et al., 2001; Clifford and Parker, 2001; Fairén et al., 2003). Similarly, an origin for the putative Deuteronilus shoreline related to coastal processes is considered unclear (Carr and Head, 2003) or likely (Webb and McGill, 2003), based on geologic and elevation relations along this feature. 
The observed present-day martian topography has been used to test the putative paleoshorelines hypothesis (Head et al., 1998, 1999; Carr and Head, 2003). The Late Hesperian Deuteronilus shoreline (Parker et al.,1989, 1993; Clifford and Parker, 2001), for example, slightly deviates from an equipotential surface, and thus has been considered to be an acceptable paleoshoreline candidate (Head et al., 1998, 1999): the elevation range along this proposed paleoshoreline is $\sim 1.1 \mathrm{~km}$ (from -3.2 to $-4.3 \mathrm{~km}$ ), with a standard deviation of $0.24 \mathrm{~km}$ from its mean altitude, which is $-3.79 \mathrm{~km}$ (Carr and Head, 2003; see their Fig. 10). Otherwise, the putative older and higher-standing Arabia shoreline (Parker et al., 1989, 1993; Clifford and Parker, 2001) deviates substantially from an equipotential surface (Head et al., 1998, 1999; Carr and Head, 2003), indicating that it may not be representative of a true shoreline. According to Carr and Head (2003), the Arabia shoreline includes a total elevation range of $\sim 5.6 \mathrm{~km}$ (from 1.6 to $-4.0 \mathrm{~km}$ ) and a standard deviation from a mean altitude $(-2.09 \mathrm{~km})$ of $1.40 \mathrm{~km}$.

The putative Noachian Meridiani shoreline (Edgett and Parker, 1997; Clifford and Parker, 2001) has been proposed to occur in northern Sinus Meridiani and western Arabia Terra regions. Elevation in this possible paleoshoreline is roughly similar to that of the Arabia shoreline in northeast Arabia, Utopia (not taking into account the Isidis basin), Elysium, and Amazonis regions. Thus, a paleoshoreline through these regions and the Meridiani shoreline (Ruiz et al., 2003; Fairén et al., 2003) is a better candidate to represent a paleoequipotential surface than the Arabia shoreline; their elevation range, although not specifically examined, would be mostly about $2 \mathrm{~km}$ (from -1 to $-3 \mathrm{~km}$; as a reference see the elevation profile along the Arabia shoreline in Fig. 5 in Carr and Head, 2003).

Evaluation of possible paleoshorelines through assessment of high-resolution topography must be made cautiously. In this paper, we use the thermal isostasy concept to show that it is not necessarily true that a paleoequipotential surface must match a present-day equipotential surface. A similar consideration takes into account the lithosphere rebound due to water unloading associated with the disappearance of an ocean with irregularly shaped margins (Leverington and Ghent, 2004). Next, we perform a first-order calculation of the relation between possible variations in the thermal state of the martian lithosphere and elevation differences, which could cause deviations in equipotentiality along the proposed paleoshorelines; note that for the purposes of this work, only long-wavelength topographic differences are relevant, since the rigidity of the martian lithosphere could prevent small-scale isostatic adjustment. Finally, we discuss our results and their implications.

\section{Elevation differences related to heat flow variations}

In this section, we use a simple model for the thermal structure of the martian lithosphere to show that heat flow variations may result in significant changes in surface elevation, and to offer an estimation of its scale. The component of the elevation of the surface relative to the free (uncompressed) height of the asthenosphere due to the thermal buoyancy of the lithosphere is given by

$H=\alpha\left(\bar{T}-T_{\mathrm{a}}\right) b$,

where $\alpha$ is the volumetric thermal expansion coefficient, $\bar{T}$ is the mean temperature of the lithosphere, $T_{\mathrm{a}}$ is the temperature of the asthenosphere, and $b$ is the thickness of the lithosphere. This equation is almost equivalent to Eq. (14) in Lachenbruch and Morgan (1990), but these authors only calculated the thermal buoyancy of the lithospheric mantle. To account for the lower crustal density, relative to that in the lithospheric mantle, the crust contribution to $H$ should be corrected by the ratio between crust and lithospheric mantle densities (here assumed as 2900 and $3500 \mathrm{~kg} \mathrm{~m}^{-3}$, respectively; for further details about this methodology see Ruiz, 2003).

Here we calculate $\bar{T}$ and $b$ in terms of the surface heat flow, assuming that there are heat sources homogeneously distributed in the crust; on Earth, crustal heat sources are strongly concentrated in the upper crust, although it has been suggested that vertical differentiation in the Mars' crust is not as important as in the Earth (e.g., McLennan, 2001). Therefore, the temperature in the crust is given by

$T_{\mathrm{z}}=T_{\mathrm{s}}+\frac{F z}{k_{\mathrm{c}}}\left(1-\frac{f z}{2 b_{\mathrm{c}}}\right)$,

where $T_{\mathrm{s}}$ is the surface temperature, $F$ is the surface heat flow, $k_{\mathrm{c}}$ is the crustal thermal conductivity, $f$ is the fraction of the surface heat flow originated by radioactive heating within the crust, and $b_{\mathrm{c}}$ is the crust thickness; the factor $f$ can be formally defined as $A b_{\mathrm{c}} / F$, where in turn $A$ is the radioactive volumetric heating rate. We do not take into account the existence of radioactive heat sources beneath the crust, and so, below the base of the crust, the heat flow is $F(1-f)$ and the temperature profile is linear and proportional to $k_{\mathrm{m}}$, the thermal conductivity of the lithospheric mantle. The mean temperature of the lithosphere is given by the quotient of the integrated lithospheric temperature profile and $b$, which in turn is the depth at which the $T_{\mathrm{a}}$ isotherm is reached.

Calculations have been performed using the following values: $\alpha=3 \times 10^{-5}{ }^{\circ} \mathrm{C}^{-1}, k_{\mathrm{c}}=2.5 \mathrm{~W} \mathrm{~m}^{-1}{ }^{\circ} \mathrm{C}^{-1}, k_{\mathrm{m}}=$ $3.5 \mathrm{~W} \mathrm{~m}^{-1}{ }^{\circ} \mathrm{C}^{-1}, \quad T_{\mathrm{a}}=1300{ }^{\circ} \mathrm{C}, \quad T_{\mathrm{s}}=0{ }^{\circ} \mathrm{C}$, and $b_{\mathrm{c}}=$ $40 \mathrm{~km}$. The assumed average surface temperature of $0{ }^{\circ} \mathrm{C}$ may be appropriate for times in which oceans could have existed, although our results are little sensitive to 
the value of $T_{\mathrm{s}}$. The crustal thickness is taken as constant since this paper addresses the component of the topography related to thermal isostasy. The assumed crustal thickness is in accordance with a typical mean crustal thickness of the northern lowlands derived from topography and gravity data (Zuber et al., 2000).

Fig. 1 shows $H$ in terms of surface heat flow for $f=0$ and $f=0.5$. There are arguments based on available geochemical data of the materials at the surface of Mars that suggest that perhaps over $50 \%$ (or even $75 \%$ ) of radioactive heat sources in this planet are placed within the crust (McLennan, 2001). Similarly in the Earth, roughly half of the heat flow lost in continental areas originates from crustal heat sources (e.g., Pollack and Chapman, 1977; Turcotte and Schubert, 2002). Calculations have been made for a range of $F$ values between 10 and $50 \mathrm{~mW} \mathrm{~m}^{-2}$, which roughly correspond to the surface heat flow range proposed for diverse regions and at varied times using estimates of the elastic thickness of the lithosphere (McGovern et al., 2004a, 2004b). For the purposes of this work, the relevant point is the relative differences of $H$, and not the absolute values obtained for this parameter (planetary topographies are referred to an arbitrary datum). Fig. 1 indicates that variations in the thermal state of the lithosphere may result in differential thermal isostasy, which in turn may result in important elevation differences, even of kilometric scale as observed for Earth (Lewis et al., 2003).

Assuming a martian paleoshoreline, the posterior attenuation, disappearance (as is expected with the waning of internal heat sources), or formation (if reheating of the lithosphere postdating the shoreline formation occurred) of heat flow variations must result in the deformation of the paleoshoreline topography,

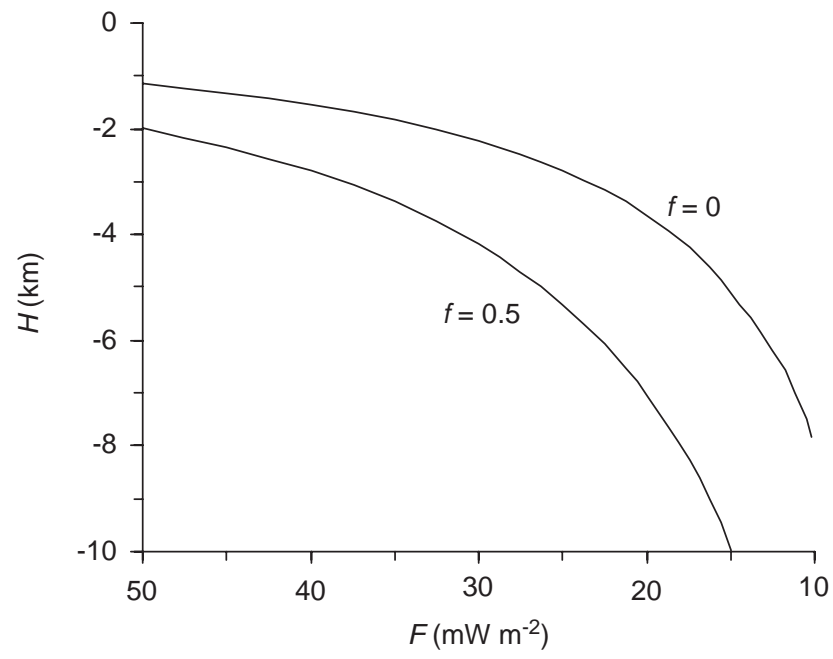

Fig. 1. Elevation over the free height of the asthenosphere in terms of surface heat flow for $f=0$ and 0.5 . Surface heat flow is represented in reverse order (describing the topographic evolution of a cooling region isostatically compensated). deviating it from an equipotential surface. This would be especially pronounced on the northern margin of the Tharsis magmatic complex, since Tharsis largely evolved during the Noachian and Hesperian (Anderson et al., 2001; Dohm et al., 2001; Phillips et al., 2001). Fig. 2 shows the relative amplitude of surface heat flow variations that can produce elevation ranges of 1 and $0.5 \mathrm{~km}$ centered on the $H$ value corresponding to a reference heat flow in the range from 10 to $50 \mathrm{~mW} \mathrm{~m}^{-2}$. The relative amplitude of heat flow variations is obtained as the quotient between the maximum and minimum heat flow that can produce positive and negative elevations, respectively, of 0.5 and $0.25 \mathrm{~km}$ with respect to the reference $H$ value. In Fig. 2 it can be seen that ancient surface heat flow variations less than a factor of $\sim 2$ may account for differences of elevation of $1 \mathrm{~km}$. An elevation range of $0.5 \mathrm{~km}$ could be produced by surface heat flow variations less than a factor of $\sim 1.5$. These values are further lowered if a substantial amount of the martian heat sources are located within the crust.
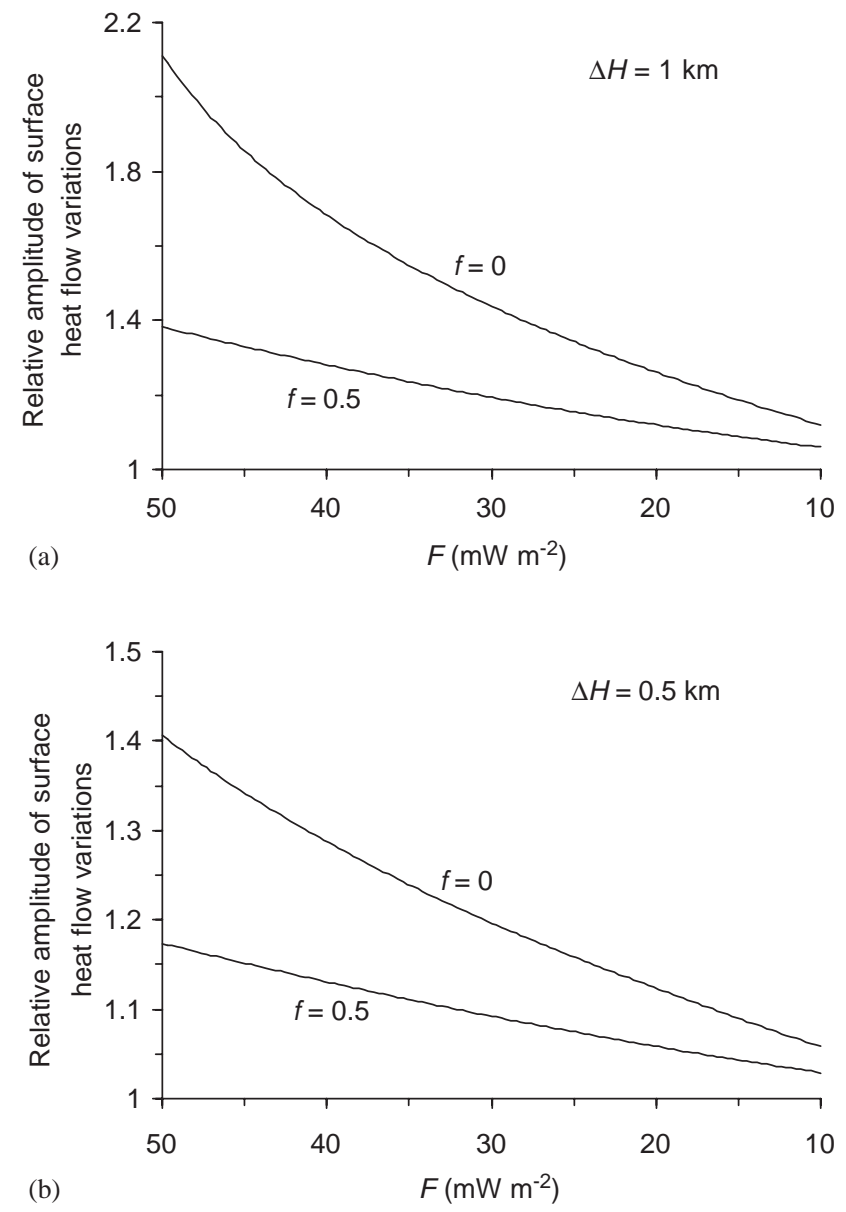

Fig. 2. Relative amplitude of surface heat flow variations that can produce elevation ranges of (a) 1 and (b) $0.5 \mathrm{~km}$ centered on the $H$ value corresponding to a reference heat flow in the range from 10 to $50 \mathrm{~mW} \mathrm{~m}^{-2}$. As in Fig. 1, surface heat flow is represented in reverse order. 
It is important to note that the value of $f$ can change along a possible paleoshoreline (due to, for example, local variations in crustal heat sources, mantle heat flow, or both) and/or with time (due to waning of radiogenic dissipation intensity or to changes in the efficiency of convective heat transfer). In any case, these possibilities are not important for the purpose of our first-order calculation, which is to show the feasibility of differential thermal isostasy histories affecting the longwavelength topography of possible martian paleoshorelines.

\section{Discussion and conclusions}

On Earth, present-day surface heat flow variations exceed an order of magnitude (e.g., Pollack et al., 1993). The majority of these variations are due to plate tectonics, with the higher heat flow associated with sea floor spreading centers. On Mars, an early phase of plate tectonism is controversial. Variations in surface heat flow in Earth's continental regions observed from contoured maps (Cermak, 1993; Pollack et al., 1993) can be higher than a factor of 2 or 3 , sufficient for significant paleoshoreline deformation (see Fig. 1). The continental heat flow depends on a wide array of factors, including radioactive heat production in the crust, local mantle heat flow, and tectonic or erosive redistribution of crustal heat producing elements (for reviews, see Beardsmore and Cull, 2001; Sandiford and McLaren, 2002). In addition, it is widely accepted that an inverse relation exists between surface heat flow and age of the last tectonothermal stabilization (e.g., Hamza, 1979; Vitorello and Pollack, 1980; Cermak, 1993), which in turn is ultimately related to plate tectonics.

In any case, heat flow variations on old and tectonothermally stable terrestrial continental regions can be as high as a factor of $\sim 1.5-2$ (e.g., Cermak, 1993; Roy and Rao, 2000; Rolandone et al., 2002). If local variations of surface heat flow of at least similar amplitude existed in Mars during any moment of its history, then our results indicate that differential thermal isostasy should result in deformation of and deviation from an equipotential surface along putative paleoshorelines. Moreover it is significant that if, as is the case for Earth, half of the surface heat flow originated from crustal heat sources at the time of the putative shoreline formation, then heat flow variations lower than a modest factor of $\sim 1.2-1.4$ may account for present-day elevation ranges of $0.5-1 \mathrm{~km}$ (if, as it seems reasonable, these heat flow variations are currently greatly attenuated). These elevation ranges are respectively similar to the \pm 1 standard deviation and the total estimated elevation range of the putative Deuteronilus shoreline, but they represent an important amount of deformation along any possible paleoshoreline.
Finally, it is important to reiterate that thermal isostasy is only one of many influences on topography. Though it is not our intention to discuss in detail the many factors that may have contributed to the modification of an equipotential surface here, we do highlight some of the possibilities, which may include modification by wind, water, cratering, tectonic, and volcanic processes (e.g., Clifford and Parker, 2001; Fairén et al., 2003), rebound of the lithosphere due to dissipation of a water body (Leverington and Ghent, 2004; for a review of isostatic and flexural effects related to changes in sea level, see Watts, 2001), flexure and/or (non-thermal) isostasy due to surface loading or erosion, or subsurface magmatic intrusions. In fact, both endogenic-driven geologic activity (probably implying vertical movements) and exogenic activity clearly postdate the possible paleoshorelines in Arabia Terra and in Tharsis and Elysium magmatic complexes (e.g., Scott and Tanaka, 1986; Greeley and Guest, 1987; Head et al., 1999; Anderson et al., 2001). Together, all these possibilities make more pressing the main argument of this paper: any paleoequipotential surface dating from an earlier Mars may very well have been since significantly modified, even in a range of elevations of a kilometric scale.

\section{Acknowledgments}

The authors thank Andrew Dombard and Jose A. Álvarez-Gómez for their comments, and Victor Baker and James Head for reviews. JR was supported by a Grant from the Spanish Secretaría de Estado de Educación y Universidades.

\section{References}

Anderson, R.C., Dohm, J.M., Golombek, M.P., Haldemann, A.F.C., Franklin, B.J., Tanaka, K.L., Lias, J., Peer, B., 2001. Primary centers and secondary concentrations of tectonic activity through time in western hemisphere of Mars. J. Geophys. Res. 106, 20,563-20,585.

Beardsmore, G.R., Cull, J.P., 2001. Crustal Heat Flow: A Guide to Measurement and Modelling. Cambridge University Press, Cambridge $324 \mathrm{p}$.

Carr, M.H., Head, J.W., 2003. Oceans on Mars: an assessment of the observational evidence and possible fate. J. Geophys. Res. 108 (E5), 5042.

Cermak, V., 1993. Lithospheric thermal regimes in Europe. Phys. Earth Planet. Inter. 79, 179-193.

Clifford, S.M., Parker, T.J., 2001. The evolution of the martian hydrosphere: implications for the fate of a primordial ocean and the current state of the northern plains. Icarus 154, 40-79.

Dohm, J.M., Ferris, J.C., Baker, V.R., Anderson, R.C., Hare, T.M., Strom, R.G., Barlow, N.G., Tanaka, K.L., Klemaszewski, J.E., Scott, D.H., 2001. Ancient drainage basin of the Tharsis region, Mars: potential source for outflow channel systems and putative oceans or paleolakes. J. Geophys. Res. 106, 32,943-32,958. 
Edgett, K.S., Parker, T.J., 1997. Water on early Mars: possible subaqueous sedimentary deposits covering ancient cratered terrain in western Arabia and Sinus Meridiani. Geophys. Res. Lett. 24, 2897-2900.

Fairén, A.G., Dohm, J.M., Baker, V.R., de Pablo, M.A., Ruiz, J., Ferris, J.C., Anderson, R.C., 2003. Episodic flood inundations of the northern plains of Mars. Icarus 165, 53-67.

Greeley, R., Guest, J.E., 1987. Geologic map of the eastern equatorial region of Mars. US Geological Survey. Miscellaneous Investigation Series. Map I-1802B, scale 1:15,000,000.

Hamza, V.M., 1979. Variation of continental mantle heat flow with age: possibility of discriminating between thermal models of the lithosphere. Pure Appl. Geophys. 117, 65-74.

Head, J.W., Kreslavsky, M., Hiesinger, H., Ivanov, M.A., Pratt, S., Seibert, N., Smith, D.E., Zuber, M.T., 1998. Oceans in the past history of Mars: test for their presence using Mars Orbiter Laser Altimeter (MOLA) data. Geophys. Res. Lett. 25, 4401-4404.

Head, J.W., Hiesinger, H., Ivanov, M.A., Kreslavsky, M.A., Pratt, S., Thomson, B.J., 1999. Possible ancient oceans on Mars: evidence from Mars Orbiter Laser Altimeter data. Science 286, 2134-2137.

Lachenbruch, A.H., Morgan, P., 1990. Continental extension, magmatism and elevation; formal relations and rules of thumb. Tectonophysics 174, 39-62.

Leverington, D.W., Ghent, R.R., 2004. Differential subsidence and rebound in response to changes in water loading on Mars: possible effects on the geometry of ancient shorelines. J. Geophys. Res. 109, E01005.

Lewis, T.J., Hyndman, R.D., Flück, P., 2003. Heat flow, heat generation, and crustal temperatures in the northern Canadian Cordillera: thermal control of tectonics. J. Geophys. Res. 108 (B6), 2316.

Malin, M.C., Edgett, K.C., 1999. Oceans or seas in the martian northern lowlands: high resolution imaging test of proposed coastlines. Geophys. Res. Lett. 26, 3049-3052.

Malin, M.C., Edgett, K.C., 2001. Mars global surveyor Mars orbiter camera: interplanetary cruise through primary mission. J. Geophys. Res. 106, 23,429-23,570.

McGovern, P.J., Solomon, S.C., Smith, D.E., Zuber, M.T., Simons, M., Wieczorek, M.A., Phillips, R.J., Neumann, G.A., Aharonson, O., Head, J.W., 2004a. Localized gravity/topography admittance and correlation spectra on Mars: Implications for regional and global evolution. J. Geophys. Res. 109, E07007.

McGovern, P.J., Solomon, S.C., Smith, D.E., Zuber, M.T., Simons, M., Wieczorek, M.A., Phillips, R.J., Neumann, G.A., Aharonson, O., Head, J.W., 2004b. Correction to "localized gravity/topography admittance and correlation spectra on mars: implications for regional and global evolution". J. Geophys. Res., in press.

McLennan, S.M., 2001. Crustal heat production and the thermal evolution of Mars. Geophys. Res. Lett. 28, 4019-4022.

Parker, T.J., Saunder, R.S., Schneeberger, D.M., 1989. Transitional morphology in west Deuteronilus Mensae, Mars: implications for modification of the lowland/upland boundary. Icarus 82, 111-145.
Parker, T.J., Gorsline, D.S., Saunders, R.S., Pieri, D.C., Schneeberger, D.M., 1993. Coastal geomorphology of the Martian northern plains. J. Geophys. Res. 98, 11,061-11,078.

Parker, T.J., Grant, J.A., Franklin, B.J., Rice, J.W., 2001. A comparison of MOC and MOLA observations of northern plains "contacts" with coastal landforms of the Bonneville basin, Utah. Lunar Planet. Sci. XXXII, 2051 abstract, (CD-ROM).

Phillips, R.J., Zuber, M.T., Solomon, S.C., Golombek, M.P., Jakosky, B.M., Banerdt, W.B., Smith, D.E., Williams, R.M.E., Hynek, B.M., Aharonson, O., Hauck, S.A., 2001. Ancient geodynamics and global-scale hydrology on Mars. Science 291, 2587-2591.

Pollack, H.N., Chapman, D.S., 1977. Mantle heat flow provinces. Earth Planet. Sci. Lett. 34, 174-184.

Pollack, H.N., Hunter, S.J., Johnson, J.R., 1993. Heat flow from the Earth interior: analysis of the global data set. Rev. Geophys. 31, 267-280.

Rolandone, F., Jaupart, C., Mareschal, J.C., Gariépy, C., Bienfait, G., Carbonne, C., Lapointe, R., 2002. Surface heat flow, crustal temperatures and mantle heat flow in the Proterozoic TransHudson Orogen, Canadian Shield. J. Geophys. Res. 107 (B12), 2341.

Roy, S., Rao, R.U.M., 2000. Heat flow in the Indian shield. J. Geophys. Res. 105, 25,587-25,604.

Ruiz, J., 2003. Amplitude of heat flow variations on Mars from possible shoreline topography. J. Geophys. Res. 108 (E11), 5122.

Ruiz, J., Fairén, A.G., de Pablo, M.A., 2003. Thermal isostasy on Mars. Lunar Planet. Sci. XXXIV, 1090 abstract, (CD-ROM).

Sandiford, M., McLaren, S., 2002. Tectonic feedback and the ordering of heat producing elements within the continental lithosphere. Earth Planet. Sci. Lett. 204, 133-150.

Scott, D.H., Tanaka, K.L., 1986. Geologic map of the western equatorial region of Mars, US Geological Survey. Miscellaneous Investigation Series. Map I-1802A, scale 1:15,000,000.

Scott, D.H., Dohm, J.M., Rice, J.W., 1995. Map of Mars showing channels and possible paleolake basins. US Geological Survey. Miscellaneous Investigation Series. Map I-2461, scale 1:30,000,000.

Tejero, R., Ruiz, J., 2002. Thermal and mechanical structure of the central Iberian Peninsula lithosphere. Tectonophysics 350, $49-62$.

Turcotte, D.L., Schubert, G., 2002. Geodynamics, second ed. Cambridge University Press, Cambridge 456 p.

Vitorello, I., Pollack, H.N., 1980. On the variation of continental heat flow with age and thermal evolution of the continents. J. Geophys. Res. 85, 983-995.

Watts, A.B., 2001. Isostasy and Flexure of the Lithosphere. Cambridge University Press, Cambridge 458 p.

Webb, V.E., McGill, G.E., 2003. Assessing the geomorphic development of putative shorelines contiguous to Northern Arabia Terra, Mars. Lunar Planet. Sci. XXXIV, 1132 abstract, (CD-ROM).

Zuber, M.T., et al., 2000. Internal structure and early thermal evolution of Mars from Mars Global Surveyor. Science 287, 1788-1793. 